\title{
Genetic epilepsy with febrile seizures plus - an overview
}

\author{
Madalina Radu', Eugenia Roza ${ }^{1,2}$, Daniel Mihai Teleanu ${ }^{2,3}$, Raluca Ioana Teleanu ${ }^{1,2}$ \\ ${ }^{1}$ Pediatric Neurology Department, "Dr. Victor Gomoiu” Children's Hospital, Bucharest, Romania \\ 2"Carol Davila" University of Medicine and Pharmacy, Bucharest, Romania \\ ${ }^{3}$ Emergency University Hospital, Bucharest, Romania
}

\begin{abstract}
Genetic epilepsy with febrile seizures plus (GEFS+) is characterized by a group of genetic epilepsies associated predominately with an autosomal dominant pattern, but also with de novo and autosomal-recessive inheritance, these last two found in a small number of cases. It was believed that GEFS+ is associated only with generalized seizures, but now the term "genetic epilepsy" is preferred because it has been demonstrated that GEFS+ is associated with both generalized and focal seizures.

The "GEFS+ family" was defined as a family with more than two individuals with GEFS+ phenotypes, including at least one with febrile seizure or febrile seizure plus.

The GEFS+ spectrum includes febrile seizures (FS), febrile seizures plus (FS+), myoclonic seizures, myoclonic-atonic seizures, absences seizures, focal or generalized seizures. The genetic mutations responsible for inhibitor-excitatory imbalance in neurons network were found in sodium voltage-gated channel alpha subunit 1 (SCN1A), sodium voltage-gated channel beta subunit 1 (SCN1B), sodium voltage-gated channel alpha subunit 2 (SCN2A), sodium voltage-gated channel alpha subunit 9 (SCN9A), gamma-aminobutyric acid type A receptor subunit gamma 2 (GABRG2), which are the main gene in GEFS+ genotype.
\end{abstract}

Keywords: GEFS+, febrile seizure, SCN1A, genetic epilepsy

\section{INTRODUCTION}

Genetic epilepsy with febrile seizures plus (GEFS+) represents a group of genetic epilepsy syndromes, associated with an autosomal dominant pattern. It was previously named and defined by Scheffer and Berkovic (1997) as generalized epilepsy with febrile seizures, "a genetic disorder with heterogeneous clinical phenotypes" because it was believed that GEFS+ was only associated with generalized seizures [1].

GEFS + was first described on a large Anglo-Australian extended family with febrile seizures having unusual duration or severity, and afebrile seizures with various types of manifestations [1].

Now the term "genetic epilepsy" is preferred due to the presence of focal as well as generalized seizures in the phenotype of these patients [2].
The definition of family with GEFS+ or "the GEFS+ family" is: "a family with more than two individuals with GEFS+ phenotypes, including at least one with FS or FS+" [3].

\section{GEFS+ SPECTRUM}

The clinical presentation of patients with GEFS + is highly variable, and the clinical spectrum extends from familial febrile seizures to more severe cases as myoclonic-atonic epilepsy or Dravet syndrome.

The pattern found in GEFS+ was observed to include febrile seizures (FS) or febrile seizures plus (FS+) alone or associated with myoclonic, myoclonic-atonic, absence, focal or generalized seizures. Thus, the phenotypes seen within GEFS+ spectrum vary from the mildest end, which include benign febrile seizures or febrile seizures plus, to 
the most severe end where we encounter a range of epileptic encephalopathies [4-7].

Zhang Y. et al. (2017) studied 31 families with GEFS+ and they succeeded to extend the phenotypic spectrum of GEFS + . Therefore, they added 3 other phenotypic groups to the spectrum: focal epilepsies without FS or FS+, genetic generalized epilepsy and afebrile generalized tonic-clonic seizures (GTCS) [2].

In another study performed on Japanese families with GEFS+, febrile seizures plus were used as the core of all clinical phenotypes and other various epilepsy types which can occur later were included afterwards. The GEFS+ spectrum that they used was classified as follows: generalized epilepsy including absence seizures, myoclonic seizures, atonic seizures and myoclonic-atonic epilepsy, partial epilepsy with temporal lobe epilepsy and frontal lobe epilepsy, unclassified epilepsy with severe myoclonic epilepsy in infancy (SMEI) and intractable childhood epilepsies with generalized tonic-clonic seizures (ICEGTC) [8].

\section{FEBRILE SEIZURES AND FEBRILE SEIZURES PLUS}

Febrile seizures (FS) are the most common phenotype in the GEFS+ spectrum [2] and are characterized clinically by tonic-clonic seizures associated with fever (over $38^{\circ} \mathrm{C}$ ) caused by a viral or bacterial infection, but without central nervous system infection. The normal age range for this type of seizure is 6 months to 6 years, with a high prevalence of seizures between 18 months and 3 years of age. FS represents the mildest phenotype of GEFS+ [9].

Febrile seizures plus (FS+) is the second most common phenotype and is similar to a classic febrile seizure, but these happen beyond the normal age range, which is after 6 years, with or without association of afebrile generalized tonic-clonic seizures, as well as febrile convulsive seizures [1]. To consider the diagnosis of FS+, patients need to fulfill one or both of the following criteria: firstly, febrile seizures that extend beyond the typical age of 6 and secondly, the occurrence of both febrile and afebrile generalized tonic-clonic seizures, which are either limited to the usual age of FS or occurring beyond that age period [10]. Usually, GTCS continue after 6 years of age and stop by adolescence, but there have been reported rare cases of afebrile GTCS in adult individuals [6,11].

\section{OTHER GEFS+ PHENOTYPES}

Childhood absence epilepsy (CAE) has been observed in GEFS + families, associated with FS or FS+, with different frequencies [2]. All of these cases carried GABRG2 mutations [12,13].

Myoclonic-atonic epilepsy (MAE) belongs to the severe end of the GEFS+ spectrum and is characterized by drop attacks due to myoclonic-atonic seizures. About one third of patients with MAE have febrile seizures at the onset of their seizure disorder and they can also have afebrile seizures [14].

Dravet syndrome or severe myoclonic epilepsy of infancy (SMEI) is a rare and malignant epilepsy syndrome, often considered part of the GEFS+ spectrum. This syndrome develops in the first year of life and has specific seizure types, a distinctive developmental course and characteristic EEG features [15]. The majority of the genetic mutations discovered in Dravet syndrome have been found in the SCN1A gene and most of these mutations were de novo SNC1A gene mutations [16]. Even so, some authors consider the Dravet syndrome as a separate spectrum, and there have been various new mutations described that have been attributed to the syndrome such as PCDH19, CHD2 and GABRA1 [17].

Focal epilepsies occur in GEFS+ families less frequently than generalized epilepsies. The most common are temporal and frontal lobe epilepsy. In the last study made by Zhang and Scheffer, it was observed that patients with temporal lobe epilepsy without a personal history of febrile seizure had a normal hippocampal structure, while individuals with temporal lobe epilepsy with a history of febrile seizures had hippocampal sclerosis [2,18-20].

Atonic seizures, which usually have a good outcome, are hard to distinguish initially from the more severe myoclonic-atonic epilepsy. They can be associated with febrile seizures and the prevalence of atonic seizures is approximately $0.5 \%$, according to the study performed by Zhang and Scheffer [2].

\section{GENETIC INHERITANCE}

Genetic epilepsy with febrile seizures benefits of a relatively wide and well-marked genetic heterogeneity. 
The major affected genes found in GEFS+ families are SCN1A, SCN1B, SCN2A, SCN9A, GABRG2 and STX1B (syntaxin 1B) [21-23].

Nine genes encode voltage-gated sodium channel $\alpha$-subunits with distinct isoforms called Nav1.1 through Nav1.9. At a central nervous system level four of these isoforms are highly expressed: Nav1.1, Nav1.2, Nav1.3, and Nav1.6. Mutations which can occur in three different central nervous system sodium channel genes split GEFS+ in two subtypes.

GEFS + type 1 is determined by mutations of SNC1B gene, encoding the $\beta 1$ subunit and GEFS+ type 2 is caused by mutations of SNC1A (chromosome 2q24-q33) gene encoding the Nav1.1 $\alpha$-subunit or the SCN2A gene encoding the Nav1.2 $\alpha$-subunit [24].

Haploinsufficiency of SCN1A determines more severe clinical expression encountered in the most severe forms of GEFS+ and severe myoclonic epilepsy in infancy (SMEI). Missense mutations in the SCN1A sodium channel gene leads to intractable childhood epilepsy with generalized tonic-clonic seizures and are the most common mutations found in GEFS+, as opposed to SMEI where the most common cause is nonsense mutations. Therefore, the severity of epileptic syndrome is suggested to come from the type of SCN1A gene mutation, leading, in the end, to complete loss of sodium channel proteins, as observed in SMEI [25-27].

\section{SCN1A}

SCN1A is one of the most causative genes in epilepsy, particularly in GEFS+ and Dravet syndrome, but is also part of genetic causes of hemiplegic migraine and autism spectrum disorder (ASD). It has a high level of expression in the central nervous system and encodes Nav1.1 which is found predominantly in the somata and dendrites of neurons [28]. Functional alterations, which are generally classified in gain of function, loss of function and partial loss of function, further determine the severity of phenotype of GEFS + spectrum. The prevalence of SCN1A gene mutations in GEFS + families is approximately $20 \%$, which is the most common mutation encountered in GEFS+ $[2,29]$. SNC1A has more impact in Dravet syndrome than in GEFS+. The mutation has been identified in more than $80 \%$ of Dravet syndrome patients, and a large majority of these patients have de novo mutations that often lead to the syndromic diagnosis. Even so, some authors consider the diagnosis of Dravet syndrome to be based on clinical aspects, rather than the presence of a SCN1A mutation [3].

It is well known that genetic epilepsy with febrile seizures plus is a complex autosomal-dominant disorder, but Brunklaus and Stewart reported rare small families with recessive inheritance, through two novel homozygous missense mutations of the SCN1A gene [30]. De novo mutations or complex inheritance has been found mostly in sporadic cases of exogamic families [31].

A comparison between SCN1A and other frequent genes found in GEFS+, such as SCN1B and GABRG2, revealed that families with SCN1A mutations had the onset of FS and FS+ at an earlier age in the first year of life than families with SCN1B mutation [32].

\section{SCN1B}

In a study made by Zhang et al. (2017), SCN1B mutations were identified in $8 \%$ of GEFS+ families [2]. The SCN1B (chromosome 19q) gene encodes the voltage-gated sodium channel $\beta$-subunit and was the first gene discovered in GEFS+ families with variable expressivity [32]. In another study, it was illustrated that patients with SCN1B gene mutations had later onset of febrile seizures in comparison with individuals with SCN1A gene mutations, 24 months respectively, 12 months [33]. Regarding focal seizures occurring in GEFS+ families and SCN1B gene mutations, the phenotype is suggestive for temporal lobe epilepsy associated or not with febrile seizure [34].

Effects of high temperature on voltage sodium-channels

The actual cause(s) of high temperature sensitivity in sodium channelopathies remain unclear, although it was analyzed from a perspective of the intrinsic nature or kinetics of each channel protein itself $[35,36]$. In mice studies, it was observed that Nav1.1 haploinsufficiency associated temperature-dependent seizures [37,38], whereas Nav1.2 haploinsufficiency or gain-of-function mutation didn't associate temperature-dependent phenotypes $[39,40]$. 
Therefore, the difference in temperature sensitivity between epilepsies caused by SCN1A and SCN2A mutation consists in their distinct expression sites and functional consequences of mutation [41]. Because Nav1.1 and Nav1.2 are very similar, the electrophysiological properties of sodium channel proteins may not explain the difference in temperature sensitivity [41]. The effect of increased temperature may be decreasing the sodium channel activity [42].

\section{SCN9A}

SCN9A is a pathogenic gene for epilepsy. This gene encodes the $\alpha$-subunit of the voltage-gated sodium channel, in particular Nav1.7 and contains 27 exons on chromosome 2q24.3. SCN9A is expressed in the neurons of the dorsal root ganglia [43], but was also described in the brain, particularly in the embryonic hippocampus, suggesting an important role in the central nervous system [44]. Several SCN9A mutations have been identified in febrile seizures-related epilepsies, particularly in GEFS+ and is also considered as a genetic modifier which, in combination with a SCN1A mutation in GEFS+ and Dravet syndrome, when contribute to a more severe phenotype $[45,46]$.

\section{GABRG2}

GABRG2 is the gene that encodes the GABA-A $\gamma-2$ receptor subunit (chromosome 5q34) and mutations have been reported in many GEFS+ families - for the first time in a large French family with GEFS+ phenotypes [47]. The prevalence of GABRG2 is considered to be around $9 \%$ in GEFS+ families $[2,48]$. In individuals within the GEFS+ spectrum, particularly with childhood absence epilepsy and a history of febrile seizures, it is more likely to encounter GABRG2 mutations $[12,13,49]$. GEFS+ type 3 is determined by mutations of the GABRG2 gene.

\section{GABRD}

GABRD is one of the genes that encode the $\delta$-subunit of the GABA-A receptor. The mechanism consists in exhibition of preferential sensitivity of $\delta$-containing GABA-A receptors to extracellular GABA concentration, mediating tonic inhibition. Thus, mutations of this gene lead to un- controlled excitation of neurons, leading to epileptic manifestations. This type of mutations has been described in GEFS+ patients as well as in juvenile myoclonic epilepsy patients [50,51].

\section{FGF13}

A gene that encodes an auxiliary protein of voltage-gated sodium channels has been described - fibroblast growth factor 13 (FGF13). The discovery was made by Puranam et al. (2015), who has described a maternally transmitted balanced translocation between chromosomes $\mathrm{X}$ and 14 . The further cellular electrophysiological studies made on mice revealed an imbalance of excitatory and inhibitory synaptic input activity, resulting in decreased inhibitory and increased excitatory synaptic inputs located in hippocampal neurons, through the deletion of one of FGF13 allele by exhibited hyperthermia [52]. FGF13 belongs to a subset of FGFs (fibroblast growth factor homologous factors) and is primarily expressed in the nervous system. The frequency of FGF13 mutations in GEFS+ is yet unknown $[53,54]$.

\section{STX1B}

The syntaxin 1B protein is encoded by STX1B gene and plays an important role in neuronal excitability and presynaptic function through its complex implication in regulation of synaptic vesicles fusion to the presynaptic membrane. A study made on two large German families has shown that STX1B mutations may lead to a wide phenotypic spectrum, which includes febrile seizures, genetic epilepsies with febrile seizures plus and also epileptic encephalopathies. Therefore, there is a link between STX1B and fever-associated epilepsy syndromes $[55,56]$.

\section{DIAGNOSIS}

Genetic epilepsy with febrile seizures plus has a wide variety of clinical manifestations. Phenotypes described in GEFS+ have a core represented by febrile seizures or febrile seizures plus. One of the most important characteristics of GEFS + is the inheritance. Therefore, when we face a child with febrile seizures, generalized or focal, we must carefully examine the family history and look for 
this type of seizures in family members. To confirm the diagnosis of GEFS+, it's necessary to test the patients and family for genetic mutations.

Genotype-phenotype correlation is unclear if a SCN1A missense mutation is identified. As a result, as said above, interpretation depends on the clinical history to determine if the patient has a phenotype that lies at the benign end of the GEFS+ spectrum or a severe phenotype such as Dravet syndrome [15].

\section{PROGNOSIS AND OUTCOME}

The outcome of children diagnosed with genetic epilepsy with febrile seizures plus varies depending on the severity of their phenotypes found within GEFS+ spectrum. The mild end of the GEFS + spectrum represented by febrile seizures or febrile seizures plus generally has a good prognosis, a good seizure control with antiepileptic drugs. The seizures may stop in late childhood or early teenage years and no intellectual disability is present. However, detailed information on seizure course, medication use, comorbidities and seizure freedom is lacking for this group of phenotypes [57]. The severe end of GEFS+ spectrum was more thoroughly analyzed. Dravet syndrome is characterized by intractable epileptic seizures and there have been numerous studies on outcome and comorbidities that showed that walking disabilities and severe behavioral problems affect most Dravet syndrome patients. These comorbidities correlate strongly with lower quality of life scores [57-59].

\section{CONCLUSIONS AND PERSPECTIVES}

Genetic epilepsy with febrile seizures plus is mainly an autosomal dominant group of epilepsy disorders with heterogeneous and complex clinical phenotypes.

The discovery of the disease-associated genes affecting the sodium channel subunits, such as SCN1A, SCN1B, SCN2A, SCN9A and the genes altering GABA receptor subunits as GABRG2, GABRGD suggest that genetic inheritance is pivotal in GEFS+. As a consequence of progress of genetic findings, GEFS + has been divided in GEFS + type 1, determined by SCN1B gene mutation, GEFS + type 2, caused by mutations of SCN2A, and GEFS+ type 3, determined by GA$\mathrm{BRG} 2$. Ion channels and neurotransmitter receptors are responsible for the seizure- causing alleles. The heterogeneous expression in GEFS+ increases the difficulty of identifying disease genes. SCN1A encodes Nav1.1 and the prevalence of SCN1A gene mutations in GEFS+ families is approximately $20 \%$ which determines the severity of phenotype of GEFS+ spectrum. Also, SCN9A is considered as a genetic modifier which causes a more severe phenotype when associated with a SCN1A mutation. SCN1B gene encodes the voltage-gated sodium channel $\beta$-subunit and it was illustrated that patients with SCN1B gene mutations had later onset of febrile seizures.

Elevated temperature sensitivity between epilepsies caused by SCN1A and SCN2A mutation may enhance synaptic transmission. The effect of increased temperature may be decreasing the sodium channel activity. GABRG2 and GABRD encode different subunits of the GABA-A receptor, mediating inhibition. Thus, mutations of these genes led to uncontrolled excitation of neurons, which results in epileptic manifestations and presentation of febrile seizures.

Given the fact that cases with de novo and autosomal-recessive inheritance of SCN1A gene mutations were described, genetic epilepsy with febrile seizures plus should not be forgotten when we are facing a child with febrile seizures and no family history of GEFS+, Dravet syndrome or other epilepsies associated with febrile seizures.

The outcome of children diagnosed with genetic epilepsy with febrile seizures plus varies depending on the severity of the phenotypes found within the GEFS+ spectrum. The cause of the high variability of GEFS + phenotypes among family members is yet to be established. The hypothesis is that other genes and environmental factors help determine the severity of the phenotype, with room to spare for more discoveries in GEFS+ genotype. 


\section{REFERENCES}

1. Scheffer IE, Berkovic SF. Generalized epilepsy with febrile seizures plus. A genetic disorder with heterogeneous clinical phenotypes. Brain. 1997;120(3):479-490.

2. Zhang YH, Burgess R, Malone JP, Glubb GC, Helbig KL, Vadlamudi L, Kivity S, Afawi Z, Bleasel A, Grattan-Smith P, Grinton BE, Bellows $\mathrm{ST}$, et al. Genetic epilepsy with febrile seizures plus: Refining the spectrum. Neurology. 2017;89(12):1210-1219.

3. Myers KA, Scheffer IE, Berkovic SF, Commission IG. Genetic literacy series: genetic epilepsy with febrile seizures plus. Epileptic Disord. 2018;20(4):232-238.

4. Scheffer I, Zhang YH. Genetic epilepsy with febrile seizures plus. In: Shorvon S, Andermann F, Guerrini R (eds.). The Causes of Epilepsy: Common and Uncommon Causes in Adults and Children. Cambridge University Press, 2011:74-77.

5. Harkin LA, McMahon JM, lona X, Dibbens L, Pelekanos JT, Zuberi SM, Sadleir LG, Andermann E, Gill D, Farrell K, et al. The spectrum of SCN1A-related infantile epileptic encephalopathies. Brain. 2007; 130(Pt 3):843-852.

6. Singh R, Andermann E, Whitehouse WP, Harvey AS, Keene DL, Seni MH, Crossland KM, Andermann F, Berkovic SF, Scheffer IE. Severe myoclonic epilepsy of infancy: extended spectrum of GEFS+? Epilepsia. 2001;42(7):837-844.

7. Doose H, Gerken H, Leonhardt R, Volzke E, Volz C. Centrencephalic myoclonic-astatic petit mal. Clinical and genetic investigation. Neuropadiatrie. 1970;2(1):59-78.

8. Ito M, Yamakawa K, Sugawara T, Hirose S, Fukuma G, Kaneko S. Phenotypes and genotypes in epilepsy with febrile seizures plus. Epilepsy Res. 2006;70(Suppl 1):S199-205.

9. Consensus statement. Febrile seizures: long-term management of children with fever-associated seizures. Pediatrics. 1980; 66(6):1009-1012.

10. Eckhaus J, Lawrence KM, Helbig I, Bui M, Vadlamudi L, Hopper JL, Scheffer IE, Berkovic SF. Genetics of febrile seizure subtypes and syndromes: a twin study. Epilepsy Res. 2013;105(1-2):103-109.

11. International League Against Epilepsy. Febrile seizures plus. Genetic epilepsy with febrile seizures plus. 2020. Available at: https://www.epilepsydiagnosis.org/syndrome/fbp-overview.html.

12. Wallace RH, Marini C, Petrou S, Harkin LA, Bowser DN, Panchal RG, Williams DA, Sutherland GR, Mulley JC, Scheffer IE, Berkovic SF. Mutant GABA(A) receptor gamma2-subunit in childhood absence epilepsy and febrile seizures. Nat Genet. 2001; 28(1):49-52.

13. Marini C, Harkin LA, Wallace RH, Mulley JC, Scheffer IE, Berkovic SF. Childhood absence epilepsy and febrile seizures: a family with a GABA(A) receptor mutation. Brain. 2003;126(Pt 1):230-240.

14. Oguni H, Hayashi K, Osawa M, Awaya Y, Fukuyama Y, Fukuma G, Hirose S, Mitsudome A, Kaneko S. Severe myoclonic epilepsy in infancy: clinical analysis and relation to SCN1A mutations in a Japanese cohort. Adv Neurol. 2005;95:103-117.

15. Scheffer IE, Zhang YH, Jansen FE, Dibbens L. Dravet syndrome or genetic (generalized) epilepsy with febrile seizures plus? Brain Dev. 2009;31(5):394-400.

16. Scheffer IE, Nabbout R. SCN1A-related phenotypes: Epilepsy and beyond. Epilepsia. 2019;60 Suppl 3:S17-S24.

17. Shi $X$, Yasumoto $S$, Kurahashi $H$, Nakagawa E, Fukasawa T, Uchiya $S$, Hirose S. Clinical spectrum of SCN2A mutations. Brain Dev. 2012;34(7):541-545.

18. Baulac S, Gourfinkel-An I, Picard F, Rosenberg-Bourgin M, Prud'homme JF, Baulac M, Brice A, LeGuern E. A second locus for familial generalized epilepsy with febrile seizures plus maps to chromosome 2q21-q33. Am J Hum Genet. 1999;65(4):1078-1085.

19. Moulard B, Guipponi M, Chaigne D, Mouthon D, Buresi C, Malafosse A. Identification of a new locus for generalized epilepsy with febrile seizures plus (GEFS+) on chromosome 2q24-q33. Am J Hum Genet. 1999;65(5):1396-1400.

20. Sugawara T, Mazaki-Miyazaki E, Ito M, Nagafuji H, Fukuma G, Mitsudome A, Wada K, Kaneko S, Hirose S, Yamakawa K. Nav1.1 mutations cause febrile seizures associated with afebrile partial seizures. Neurology. 2001;57(4):703-705.
21. Wallace RH, Scheffer IE, Barnett S, Richards M, Dibbens L, Desai RR, Lerman-Sagie T, Lev D, et al. Neuronal sodium-channel alpha1-subunit mutations in generalized epilepsy with febrile seizures plus. Am J Hum Genet. 2001;68(4):859-865.

22. Audenaert D, Schwartz E, Claeys KG, Claes L, Deprez L, Suls A, Van Dyck T, Lagae L, Van Broeckhoven C, Macdonald RL, De Jonghe P. A novel GABRG2 mutation associated with febrile seizures. Neurology. 2006;67(4):687-690.

23. Schubert J, Siekierska A, Langlois M, May P, Huneau C, Becker F, Muhle H, Suls A, Lemke JR, et al. Mutations in STX1B, encoding a presynaptic protein, cause fever-associated epilepsy syndromes. Nat Genet. 2014;46(12):1327-1332.

24. Barela AJ, Waddy SP, Lickfett JG, Hunter J, Anido A, Helmers SL, Goldin AL, Escayg A. An epilepsy mutation in the sodium channel SCN1A that decreases channel excitability. J Neurosci. 2006;26(10):2714-2723.

25. Lossin C, Rhodes TH, Desai RR, Vanoye CG, Wang D, Carniciu S, Devinsky O, George AL, Jr. Epilepsy-associated dysfunction in the voltage-gated neuronal sodium channel SCN1A. J Neurosci. 200;23(36):11289-11295.

26. Waxman SG. Channel, neuronal and clinical function in sodium channelopathies: from genotype to phenotype. Nat Neurosci. 2007;10(4):405-409.

27. Meisler MH, Kearney JA. Sodium channel mutations in epilepsy and other neurological disorders. J Clin Invest. 2005;115(8):2010-2017.

28. Trimmer JS, Rhodes KJ. Localization of voltage-gated ion channels in mammalian brain. Annu Rev Physiol. 2004;66:477-519.

29. Mantegazza M, Broccoli V. SCN1A/NaV 1.1 channelopathies: Mechanisms in expression systems, animal models, and human iPSC models. Epilepsia. 2019;60(Suppl 3):S25-S38.

30. Brunklaus A, Ellis R, Stewart $H$, Aylett S, Reavey E, Jefferson R, Jain R, Chakraborty S, Jayawant S, Zuberi SM. Homozygous mutations in the SCN1A gene associated with genetic epilepsy with febrile seizures plus and Dravet syndrome in 2 families. Eur $\mathrm{J}$ Paediatr Neurol. 2015;19(4):484-488.

31. Myers KA, Burgess R, Afawi Z, Damiano JA, Berkovic SF, Hildebrand MS, Scheffer IE. De novo SCN1A pathogenic variants in the GEFS+ spectrum: Not always a familial syndrome. Epilepsia. 2017;58(2):e26-e30.

32. Wallace RH, Wang DW, Singh R, Scheffer IE, George AL, Jr., Phillips HA, Saar K, Reis A, Johnson EW, Sutherland GR, Berkovic SF, Mulley JC. Febrile seizures and generalized epilepsy associated with a mutation in the Na+-channel beta1 subunit gene SCN1B. Nat Genet. 1998;19(4):366-370.

33. Sijben AE, Sithinamsuwan $P$, Radhakrishnan A, Badawy RA, Dibbens L, Mazarib A, Lev D, Lerman-Sagie T, Straussberg R, Berkovic SF, Scheffer IE. Does a SCN1A gene mutation confer earlier age of onset of febrile seizures in GEFS+? Epilepsia. 2009;50(4):953-956.

34. Scheffer IE, Harkin LA, Grinton BE, Dibbens LM, Turner SJ, Zielinski MA, Xu R, Jackson G, Adams J, Connellan M, Petrou S, Wellard RM, Briellmann RS, Wallace RH, Mulley JC, Berkovic SF. Temporal lobe epilepsy and GEFS+ phenotypes associated with SCN1B mutations. Brain. 2007;130(Pt 1):100-109.

35. Egri C, Ruben PC. A hot topic: temperature sensitive sodium channelopathies. Channels (Austin). 2012;6(2):75-85.

36. Thomas EA, Hawkins RJ, Richards KL, Xu R, Gazina EV, Petrou S. Heat opens axon initial segment sodium channels: a febrile seizure mechanism? Ann Neurol. 2009;66(2):219-226.

37. Cao D, Ohtani H, Ogiwara I, Ohtani S, Takahashi Y, Yamakawa K, Inoue $Y$. Efficacy of stiripentol in hyperthermia-induced seizures in a mouse model of Dravet syndrome. Epilepsia. 2012;53(7):1140-1145.

38. Oakley JC, Kalume F, Yu FH, Scheuer T, Catterall WA. Temperatureand age-dependent seizures in a mouse model of severe myoclonic epilepsy in infancy. Proc Natl Acad Sci USA. 2009;106(10):39943999.

39. Planells-Cases R, Caprini M, Zhang J, Rockenstein EM, Rivera RR, Murre C, Masliah E, Montal M. Neuronal death and perinatal lethality 
in voltage-gated sodium channel alpha(II)-deficient mice. Biophys $\mathrm{J}$. 2000;78(6):2878-2891.

40. Kearney JA, Plummer NW, Smith MR, Kapur J, Cummins TR, Waxman SG, Goldin AL, Meisler MH. A gain-of-function mutation in the sodium channel gene Scn2a results in seizures and behavioral abnormalities. Neuroscience. 2001;102(2):307-317.

41. Yamakawa K. Mutations of Voltage-Gated Sodium Channel Genes SCN1A and SCN2A in Epilepsy, Intellectual Disability, and Autism. In: Sala C, Verpelli C (eds). Neuronal and Synaptic Dysfunction in Autism Spectrum Disorder and Intellectual Disability. Academic Press, 2016;233-251.

42. Hodgkin AL, Katz B. The effect of temperature on the electrical activity of the giant axon of the squid. J Physiol. 1949; 109(1-2):240-249.

43. Catterall WA. From ionic currents to molecular mechanisms: the structure and function of voltage-gated sodium channels. Neuron. 2000;26(1):13-25.

44. Mechaly I, Scamps F, Chabbert C, Sans A, Valmier J. Molecular diversity of voltage-gated sodium channel alpha subunits expressed in neuronal and non-neuronal excitable cells. Neuroscience. 2005;130(2):389-396.

45. Singh NA, Pappas C, Dahle EJ, Claes LR, Pruess TH, De Jonghe P, Thompson J, Dixon M, Gurnett C, Peiffer A, White HS, Filloux F, Leppert MF. A role of SCN9A in human epilepsies, as a cause of febrile seizures and as a potential modifier of Dravet syndrome. PLoS Genet. 2009;5(9):e1000649.

46. Ding J, Zhang JW, Guo YX, Zhang YX, Chen ZH, Zhai QX. Novel mutations in SCN9A occurring with fever-associated seizures or epilepsy. Seizure. 2019;71:214-218.

47. Baulac S, Huberfeld G, Gourfinkel-An I, Mitropoulou G, Beranger A, Prud'homme JF, Baulac M, Brice A, Bruzzone R, LeGuern E. First genetic evidence of GABA(A) receptor dysfunction in epilepsy: a mutation in the gamma2-subunit gene. Nat Genet. 2001; 28(1):46-48.

48. Li X, Guo S, Liu K, et al. GABRG2 Deletion Linked to Genetic Epilepsy with Febrile Seizures Plus Affects the Expression of GABAA Receptor Subunits and Other Genes at Different Temperatures. Neuroscience. 2020;438:116-136.
49. 49. Johnston AJ, Kang JQ, Shen W, Pickrell WO, Cushion TD, Davies JS, Baer K, Mullins JGL, Hammond CL, Chung SK, Thomas $\mathrm{RH}$, White C, Smith PEM, Macdonald RL, Rees MI. A novel GABRG2 mutation, p.R136*, in a family with GEFS+ and extended phenotypes. Neurobiol Dis. 2014;64:131-141.

50. Carver CM, Reddy DS. Neurosteroid Structure-Activity Relationships for Functional Activation of Extrasynaptic deltaGABA(A) Receptors. J Pharmacol Exp Ther. 2016;357(1):188-204.

51. Wei F, Yan LM, Su T, He N, Lin ZJ, Wang J, Shi YW, Yi YH, Liao WP. Ion Channel Genes and Epilepsy: Functional Alteration, Pathogenic Potential, and Mechanism of Epilepsy. Neurosci Bull. 2017:33(4):455-477.

52. Puranam RS, He XP, Yao L, Le T, Jang W, Rehder CW, Lewis DV, $\mathrm{McNamara}$ JO. Disruption of Fgf13 causes synaptic excitatoryinhibitory imbalance and genetic epilepsy and febrile seizures plus. J Neurosci. 2015;35(23):8866-8881.

53. Wong JC, Escayg A. Fgf13 Identified as a Novel Cause of GEFS. Epilepsy Curr. 2016;16(2):112-113.

54. Rigbye KA, van Hasselt PM, Burgess R, Damiano JA, Mullen SA, Petrovski S, et al. Is FGF13 a major contributor to genetic epilepsy with febrile seizures plus? Epilepsy Res. 2016;128:48-51.

55. Schubert J, Siekierska A, Langlois M, et al. Mutations in STX1B, encoding a presynaptic protein, cause fever-associated epilepsy syndromes. Nat Genet. 2014;46(12):1327-1332.

56. Deng $\mathrm{H}$, Zheng $\mathrm{W}$, Song $Z$. The genetics and molecular biology of fever-associated seizures or epilepsy. Expert Rev Mol Med. 2018;20:e3.

57. de Lange IM, Gunning B, Sonsma ACM, van Gemert L, van Kempen $M$, Verbeek NE, Sinoo C, Nicolai J, Knoers N, Koeleman BPC, Brilstra EH. Outcomes and comorbidities of SCN1A-related seizure disorders. Epilepsy Behav. 2019;90:252-259.

58. Escayg A, MacDonald BT, Meisler MH, Baulac S, Huberfeld G, An-Gourfinkel I, Brice A, LeGuern E, Moulard B, Chaigne D, Buresi $C$, Malafosse A. Mutations of SCN1A, encoding a neuronal sodium channel, in two families with GEFS+2. Nat Genet. 2000; 24(4):343-345.

59. Catterall WA, Kalume F, Oakley JC. NaV1.1 channels and epilepsy. J Physiol. 2010;588(Pt 11):1849-1859. 